\title{
Los Seres Humanos Matter: A Hispanic Health Story from Texas
}

\author{
John W. Davis
}

Latino health deserves intense focus in promoting a just health care system. Despite the surprisingly positive health outcomes associated with the "Hispanic Paradox" phenomenon, the trend of Latino immigrants tending to have better health outcomes than other minorities, linguistic issues persist. The following essay is a combination of actual patient encounters through my experiences serving Spanishspeaking patients, as a medical student and Spanish speaker, and a reflection on the clash between impersonal interpretation services and Hispanic cultural values. I then present potential initiatives to improve rapport in patient encounters while maintaining the standard of care across foreign language barriers (J Am Board Fam Med 2019;32:115-117.)

Keywords: Communication Barriers, Hispanic Americans, Immigrants, Standard of Care, Texas

It was a typical day in the Gulf Coast of Texas: the sun was shining, the sweat was dripping constantly off the tips of everyone's noses, and I was walking toward the student-run free clinic. Like many others, I wanted to make the free clinic a priority even as life and medical school became busy. And it was busier than ever. I was set to be married in just 2 weeks, and I was in the thick of midterm examination season. The chaos of the week and the pounding headache from sleep deprivation nearly convinced me to stay home that day.

What convinced me to go, though, was the ringing reminder of a 50-year-old Hispanic female voice, "Rosario," that continued to replay in my ears. A patient with severe headaches and near constant nausea secondary to adult hydrocephalus, she had been overlooked for an appointment by our clinic for 7 months now, since just before I came to school. The reason? She had immigrated here some 10 years ago and had yet to learn English. No one

This article was externally peer reviewed.

Submitted 23 July 2018; revised 4 October 2018; accepted 8 October 2018.

From University of Texas, Medical Branch at Galveston, Galveston, TX.

Funding: John Davis is funded by a T-32 combined degree program grant, and by the Albert Schweitzer Fellowship. No funds were allocated for the writing of this essay. Conflict of interest: none declared.

Corresponding author: John W. Davis, University of Texas, Medical Branch at Galveston, Galveston, TX 77555 (E-mail: jowdavis@utmb.edu). on our scheduling team at the time could speak Spanish, and she had simply fallen through the cracks.

When I called her that day to finally schedule her appointment, I deservedly got an earful of frustration. As my heart and eyes began to swell with her story laid out in detail after brutal detailgetting fired because she could not concentrate at work, losing her husband because he had been driven away by her suffering, and even losing her sanity as she sat completamente sola (completely alone) in her house once she had been abandoned by her family-Rosario delivered dagger to my heart.

"I've been trying to be scheduled here since January. I got a call from someone who could barely talk to me 6 months ago, and now all of a sudden you cheerily call me to set up an appointment. How do you explain that?"

"It is that ... well, no one had told me what was going on, and we did not have anyone else who could speak Spanish on our team to call you."

"Are you serious? The reason I've been laid out in all this pain for months on end is because they put a team together without anyone who speaks Spanish? I am a ser bumano (human being), just like each of you."

I did not know what to say. She was right. Our patients who do not speak English, much like nonEnglish speaking immigrant patients anywhere else 
in the United States, have the deck stacked against them when it comes to patient care. This patient had tremendously suffered because of infrastructural neglect. In a community where almost onethird of the population is Latino, we had failed to assign a single Spanish speaker to our call team.

This issue with infrastructure could potentially be attributed to a lack of volunteer mobilization. In a school with one of the most diverse medical school classes in the nation, we are surprisingly short on Spanish-speaking volunteers at our clinic. There are 2 Spanish-speaking student leaders at our clinic; only 1 is a native speaker. However, it seems more appropriate to blame an education system that metaphorically ignores the growing need for Spanish-speaking and bilingual clinicians of other languages in a rapidly globalizing world. The current political atmosphere aside, high school and elementary school students are rarely encouraged to pursue an advanced study of foreign languages. Technically speaking, Spanish could even be construed a "native" language of the United States, as it is the primary language spoken by many here. In any case, by the time medical students arrive on campus, their opportunities to learn other languages and cultures are usually slim.

In speaking to my fiancé later that night, I recounted a similar disappointment in my helplessness to affect any real change for people like Rosario. Despite my discouragement, though, I felt satisfied in knowing that I had now signed up for full-time duty on the call team, and this was not going to happen again. At least not if I had any influence.

Of course, it happened again, albeit in a different setting. Just a week later, I again showed up at the clinic. The same pounding headache, the same profuse sweating that seems a trademark of practicing medicine in the Gulf Coast of Texas. Since I had worked overtime, partly out of shame, partly out of determination, on the scheduling team to prioritize Spanish speakers' appointment scheduling, the clinic had now an overflow of Spanish speakers and no one to see them. Because we had no Spanish speaking staff at the clinic that day, I was asked to translate for a short physical examination.

Speaking Spanish with patients has always been a worthwhile opportunity for me to bond with someone not expecting to receive a compassionate ear. As a junior medical student, though, I often work in a team with a student who speaks no Span- ish whatsoever. Under this team-based approach, I went to see "Gloria" with another medical student, "Jeff." The patient was about 50 years old, just like Rosario, a bit overweight, diabetic, depressed, and suffering from arthritic joint pain. Jeff is a compassionate student; he tries to introduce himself and ask about any medication allergies in Spanish, though his language skills seem to miss their mark.

"Me llamo es Jeff. Quieres ser alergias? (I call myself is Jeff. Do you want to be allergies?)"

Gloria looks at me and laughs, but her eyes start to water as she turns away. She may have appreciated the attempt on a different day, but today it is a reminder that on the Gulf Coast, those who can help simply do not understand her. I offer to stick around to chat with Gloria while Jeff presents her case to the attending physician. We discuss how the doctors here try hard, maybe even harder than most, but they just cannot do much to help her. "Even when they want to hear me," she said, "they could not if they tried." Is something always better than nothing?

There are many theories and problems associated with communicating across language barriers. As many know, the use of phone-based interpretation has proliferated, as it connects highly trained linguistic professionals with clinicians attempting to provide competent care. However, Gloria (like many other Hispanic patients express) was quite averse to phone interpretation. She mentioned that the poor phone signals at our free clinic made her feel as if her thoughts were not being accurately relayed. Furthermore, there have been multiple concerns with phone call interpretations' effect on patient rapport. One study, a quasi-randomized controlled trial, found that the use of phone call interpreters significantly shortened the patient encounter compared with same-language encounters. ${ }^{1}$ Although there are many possible reasons for this, perhaps one is cutting out the personal, rapport-building efforts one would usually make when speaking the same language: questions like "how are you?" and "how is your family?" may be cut away when using interpreter services.

I could tell you much more about Gloria's case: about how she had suffered and how she had been overlooked by the medical system because of where she was from. But that narrative has already been told. I can only tell you that I spent an hour with her that night, listening to her cry desperately for some relief. Seven of her 10 siblings had died 
within the past 2 years from an unknown disease, and her nephew too had passed. The doctors had counseled her on sleep hygiene and proper antidepressant therapy, "but these are for the body, and do nothing for my soul," she tells me. She thanks me for speaking with her, face to face. She has never spoken to a health care professional in person before, only by phone.

Many jokes and punchlines describe the quality of foreign language instruction here in the United States, but in a small, free clinic setting, I see the painful ramifications daily. Rosario and Gloria are microcosms of the great divide practitioners face in caring for people when we do not have the right ears to hear them. Why not take the time to learn basic greetings and leave-takings for the patients whom we serve, at least for some of the more common languages? We should learn a little of their culture, of their expectations even, and make certain the medical infrastructure we oversee does not ignore needs like it did for these two people. It is important to understand that a remote, phonebased medical interpreter is an inadequate substitute when Latino values of personalismo (personal relationships), confianza (trust), and calor bumano (human warmth) underlie a Spanish-speaking patient's desire to interact with a physical person. This would be ideally implemented in the medical curriculum, but its absence is no excuse, at least, not to these patients. Although interpreters can and should be intimately involved in delivering highquality care to non-English speaking patients in the United States, using their assistance while neglecting to develop our own cultural and lingual fluency would be to shortchange these populations. Furthermore, we have the opportunity to press for these curricular opportunities at the medical educational level and even before that. The "Spanish desert" on the Gulf Coast of Texas has been unkind to many, but it is not too late to improve the future for those who care for patients with limited English. Los seres bumanos matter, in any language.

To see this article online, please go to: http://jabfm.org/content/ 32/1/115.full.

\section{Reference}

1. Locatis C, Williamson D, Gould-Kabler C, et al. Comparing in-person, video, and telephonic medical interpretation. J Gen Intern Med. 2010;25:345-50. 